\title{
A reforma do Estado e da educação na década de 1990: a refuncionalização da escola via implementação da eficiência mercadológica ${ }^{1}$
}

\author{
Enédio Naider Filho \\ Licenciado em Filosofia, \\ História e Pedagogia - Unifai; \\ Mestrando em Educação - PPGE - Uninove; \\ Diretor de Escola - Rede Municipal \\ Ensino São Paulo; \\ Professor Educação Básica II - História - Rede \\ Estadual Ensino São Paulo. \\ São Paulo - SP [Brasil] \\ enedionf@ig.com.br
}

Neste artigo, analisam-se alguns dos possíveis impactos sobre o trabalho pedagógico nas instituições escolares da rede pública brasileira, decorrentes das reformas do Estado e da educação implantadas no Brasil na década de 1990. Essas reformas adotaram princípios da teoria do social-liberalismo que faz uma crítica ao Estado do Bem-Estar Social, responsabilizando-o pela crise econômica do período. Essa vertente defende a necessidade de reformar o Estado e suas instituições para corrigir distorções e aumentar sua eficiência, inserindo, assim, o Brasil na nova organização do modo de produção capitalista. Considerando o campo da educação como parte constituinte do Estado capitalista, ele também será objeto das propostas de reforma do Estado, na medida em que o discurso dos reformistas afirma ser sua ineficiência a responsável pelo fracasso escolar.

Palavras-chave: Eficiência mercadológica. Gestão escolar. Políticas educacionais. Reforma do Estado e da educação. 


\section{Introdução}

O ponto de partida deste estudo é o pressuposto de que a prática escolar é uma atividade social, pois está inserida numa determinada organização de sociedade, a escola, da qual absorve suas características, refletindo-as, ao mesmo tempo, no seu cotidiano de organização e prática. Isso significa que a prática escolar não pode ser tratada como uma atividade neutra, por não ocorrer no vazio, isto é, desvinculada de um determinado modo de organização social [...]. Ela é concreta e prática, materializandose em condições historicamente determinadas para atender às necessidades e interesses de grupos e ou de pessoas.

Nesse sentido, no plano político e social, durante a década de 1980, a centralização e o autoritarismo político da sociedade brasileira começavam a sofrer pressões. Iniciava-se o período de "redemocratização" política e, conseqüentemente, a luta pela abertura democrática e pela descentralização do planejamento, ou seja, por formas mais flexíveis de planejamento voltadas para o poder local.

No plano educacional, observa-se que, a partir daquela década, o processo de democratização da sociedade brasileira impulsionou mudanças na área de gestão em todo o sistema educacional. Com a promulgação da Constituição Federal de 1988, a "gestão democrática do ensino público, ficou garantida como um dos princípios educacionais na forma da lei;" (Art. 206, VI). Em 1996, com a implantação da Lei de Diretrizes e Bases da Educação Nacional nº 9.394, o princípio de "gestão democrática" para o ensino público apresentava-se como o caminho para a superação de uma organização educacional autoritária e centralizadora. Esse movimento preocupava-se com a qualidade do ensino, procurando superar a dimensão quantitativa enfatizada até então.
No âmbito da estrutura interna do Estado, com a crise disseminada pelo endividamento externo, pelos planos de estabilização e pelos ajustes macroeconômicos, novas relações de poder passaram a se configurar, impulsionando o redirecionamento de estratégias econômicas, políticas e sociais do Estado para atender às novas exigências do mercado capitalista. Nesse cenário, com a interferência dos organismos multilaterais, (CEPAL, BM), sedimentou-se o processo de globalização e de concentração de capitais, exigindo um novo tipo de ser humano para a fase da mecanização do modo de produção capitalista que se consolidava. Nesse sentido, Neves (1999, p. 18) afirma que “[...] os novos padrões de sociabilidade humana requerem, por sua vez, um novo espaço social de aprendizagem profissional e cultura, e a escola, uma vez re-funcionalizada, apresenta-se como lócus privilegiado para conformar esses homens de novo tipo."

Ao analisar a interferência dos organismos multilaterais na elaboração das propostas das políticas educacionais brasileiras, Torres (2000, p. 138) afirma:

\section{[...] as propostas do BM (Banco Mundial)} para a educação são feitas basicamente por economistas dentro da lógica e da análise econômica. A relação custo-benefício e a taxa de retorno constituem as categorias centrais a partir das quais se define a tarefa educativa, as prioridades de investimento $[\ldots]$ os rendimentos, e a própria qualidade.

O enfoque economicista das políticas educacionais adentrou os anos 1990, reafirmando ainda mais a centralidade da educação como garantia para o desenvolvimento social e econômico. Analisando 
as políticas do Estado para a área educacional nos anos 1980, Oliveira (1997, p. 83) assim se referia à década subseqüente:

Os anos 90 devem significar a década da transformação produtiva, de mudanças qualitativas para alcançar competitividade no novo mercado mundial. Daí a importância atribuída à educação que deve estar em estreita vinculação com o mundo do trabalho, da produção. Mais uma vez é necessário eliminar a pobreza, sem o que não é possível o desenvolvimento.

Nos anos 1990, as orientações dos organismos multilaterais e as políticas para a educação ampliaram o leque de abrangência das reformas educativas vinculadas ao trabalho na perspectiva econômica de livre mercado, da globalização e do Estado mínimo (Plano Educacional de Educação para Todos, Brasília, MEC, 1993). Essa perspectiva situa e acentua a preocupação com a gestão do sistema educacional e da escola. Para a gestão do sistema educacional, "[. . . ] a ordem é reduzir o insucesso para alcançar menor desperdício de recursos humanos e materiais" (SHIROMA et al., 2002, p. 13). E para a gestão da escola, buscou-se, por meio de parcerias, a racionalidade financeira e a maior produtividade, articulando-se com o mercado. Nesse contexto, enfatizou-se a gestão da educação no gerenciamento financeiro.

Portanto, a reforma da Educação passou a ser sugerida e enfatizada a partir da argumentação de que os problemas técnicos e os fatores internos é que impedem o desenvolvimento eficaz dos sistemas e das unidades escolares. Além disso, justificou-se que as reformas pretendidas não obteriam êxito se não houvesse mecanismos eficientes para gerenciar as ações implantadas e os resultados obtidos. Assim, pode-se afirmar que a reforma educacional, posta em prática na década de 1990, tinha como base os mesmos pressupostos que orientavam e exigiam a reforma do Estado e fundamentam as estratégias de consolidação da atual configuração do modo capitalista de produção. Entre esses pressupostos destaca-se o controle sobre o trabalho e a vida dos trabalhadores. A lógica das propostas de reforma da Educação se detém na análise dos fatores internos da escola e do sistema escolar, apontados como responsáveis pelos baixos índices de desempenho e eficácia. Tais análises não operam um avanço, na medida em que desconsideram os aspectos históricos, políticos, econômicos e sociais como componentes da prática escolar.

De acordo com um conjunto de documentos analisados, dos quais se destaca "Prioridades e estratégias para a educação", elaborado pelo Banco Mundial, a reforma da Educação é exigida tendo em vista a idéia de que a educação básica é relevante não só para o crescimento econômico e a redução da pobreza, mas também para atender às transformações que ocorrem no mercado de trabalho e têm por base a evolução tecnológica. Esse quadro exige uma reforma do sistema de produção e difusão de conhecimentos, que hoje se revela incapaz de acompanhar os avanços tecnológicos e a transformação produtiva.

Para entender a articulação existente entre a reforma do Estado e da educação básica, implantadas a partir da década de 1990, faz-se necessário discutir a reforma do Estado proposta pela teoria social-liberal. Para os teóricos do social-liberalismo, somente o Estado burguês é efetivamente capaz de garantir as condições necessárias para a reprodução das relações capitalistas de produção, ou seja, tendo em vista a necessidade de um Estado em geral 
e, particularmente, de um Estado burguês, não se trata de descartá-lo, mas de rever os entraves para a reprodução eficaz desse modelo social. Assim, conforme afirma Mészáros (2002, p. 109),

[...] o Estado se afirma como pré-requisito indispensável para o funcionamento permanente do sistema do capital, em seu microcosmo e nas interações das unidades particulares de produção entre si, afetando intensamente tudo, desde os intercâmbios locais mais imediatos até os de nível mais mediato da crise estrutural do capital, reformá-lo, assim como a todas as práticas e instituições relacionadas a ele, incluindo suas formas de organização.

Nesse sentido, na discussão das reformas do Estado brasileiro e da Educação, como parte do processo de reformas estruturais, implantadas no contexto da globalização contemporânea - para assegurar a formação social capitalista e, desse modo, produzir as condições necessárias à reprodução das relações de produção, empreendidas nesse modelo social - é preciso tratar da chamada crise do Estado.

Para consolidar-se como padrão de Estado, o neoliberalismo utiliza o argumento de que o Estado é o principal responsável quando se trata da crise pela qual passa o modo de produção capitalista. Assim, a ineficiência do Estado para atuar nos setores econômicos e sociais, agravada pelos gastos excessivos com os direitos sociais, estaria provocando a crise do capital. Dessa maneira, a solução consistiria em rever as formas de intervenção estatal, que, nessa perspectiva, deveriam pautar-se na lógica do livre mercado.
Para os teóricos neoliberais, o culpado pela crise não seria o modo de produção capitalista, que deve ser fortalecido, mas o funcionamento ineficiente do Estado que se tem mostrado incapaz de orientar o desenvolvimento da produção. Nesse contexto, os neoliberais defendem que esse quadro somente poderá ser revertido se o mercado retomar a direção da economia.

Diante dessa compreensão da crise do Estado, tem-se, no conjunto de princípios que orientam os neoliberais, a idéia de que é preciso reformá-lo para aumentar sua eficiência e capacidade de regulação. De acordo com essa orientação político-teórica, para o Brasil inserir-se na competitividade internacional posta pelo contexto da globalização, é necessário promover a reforma do Estado, uma vez que esse novo cenário lhe reserva novas funções, competências, estratégias administrativas e institucionais.

Portanto, considerando o papel atribuído ao Estado burguês de assegurar a dominação de uma classe sobre a outra e produzir as condições necessárias para a expansão e acumulação do capital, é possível afirmar que, por meio da reforma do Estado e da Educação Básica, o que se faz é garantir a produção e reprodução dos interesses do mercado. Nas propostas de reforma da educação, fica evidente que não se trata de negar-lhe a importância no contexto da organização e manutenção do modo de produção capitalista. O que se requer é a sua adequação às exigências da nova ordem econômica que se estrutura. Nessa perspectiva, pode-se afirmar que a reforma proposta visa a resguardar o papel político e ideológico da Educação na inserção do Brasil na nova ordem econômica, imposta pelo modo de produção capitalista. Segundo Shiroma et al. (2002, p. 64), as reformas do Estado e da Educação Básica, implementadas na década de 1990, estariam formuladas no documento produzido pela Comissão Econômica 
para a América Latina e o Caribe (CEPAL), em 1992, "Educação e Conhecimento: eixo da transformação produtiva com eqüidade":

O documento enfatiza a necessidade de reformas administrativas que operassem uma transmutação do Estado administrador e provedor para um Estado avaliador incentivador e gerador de políticas. Para tanto, recomendava que se conjugassem esforços de descentralização e de integração, que pode ser traduzido em desconcentração de tarefas e concentração de decisões estratégicas.

De acordo com esse documento, que, aliás, revela-se fundamental para a compreensão das reformas da educação básica e da gestão escolar no Brasil na década de 1990, "O Estado administrador, provedor, benevolente de recursos deve ser substituído pelo estado avaliador, incentivador e gerador de políticas de médio e longo prazo." (SHIROMA et al., 2002, p. 64). Assim, pode-se afirmar que a CEPAL alinhou as propostas de educação na década de 1990 à reestruturação econômica em curso, “[. . .] cujo eixo seria a incorporação de conhecimentos no processo produtivo" (SHIROMA et al., 2002, p. 71).

Essa tônica também está presente no Relatório para a United Nations - Educational, Scientific and Cultural Organisation (Unesco), da Comissão Internacional sobre Educação para o século XXI, conhecido como Relatório Jacques Delors (1999), que defende que o mundo capitalista caminha em direção à efemeridade e ao instantâneo e, por isso, considera necessário que se busquem soluções rápidas. E como a educação é um caminho de longo prazo, torna-se necessária a existência de uma "sociedade educativa" na qual os indivíduos tenham "educação ao longo de toda a vida", ou seja, que possam aprender tanto na escola quanto em todos os momentos da sua vida. Esses momentos contêm os meios econômicos, sociais e culturais que propiciam a aprendizagem. A base dessa educação deverá pautar-se por quatro pilares: aprender a viver juntos; aprender a conhecer; aprender a fazer, e aprender a ser.

Criar um espírito novo que, graças precisamente a esta percepção das nossas interdependências, graças a uma análise partilhada dos riscos e dos desafios do futuro, conduza à realização de projetos comuns ou a 'uma gestão inteligente e apaziguadora dos inevitáveis conflitos' [...] (DELORS, 1999, p. 19, grifos nossos).

No Relatório Delors, o aclamado espírito democrático na escola está sendo evocado, não para garantir a participação dos envolvidos no processo pedagógico na construção de um plano educacional coletivo, mas como modelo e garantia de sustentação financeira às reformas e melhorias. Diante disso, subtende-se que as reformas propostas, decorrentes do sistema econômico, são imperativas.

Entender as reformas da gestão escolar e da educação básica implantadas no Brasil na década de 1990, sob a ótica social-liberal, requer a leitura e análise de uma das intelectuais mais representativas da tendência liberal modernizante no Brasil, Guiomar Namo de Mello. Mello (1990), na obra Social democracia e educação: teses para discussão, defende a idéia de que a educação está em crise e a escola tem-se mostrado ineficiente porque o Estado estaria em crise. Diante dessa ineficiência, a autora propõe uma série de mecanismos/estratégias que seriam capazes de re- 
verter e transformar os fatores internos da escola, responsáveis pela ineficiência pelos altos índices de evasão e repetência, e pelo desperdício de recursos na manutenção da escola.

De acordo com a autora, para implantar a pretendida reforma da gestão escolar, é preciso rever o modelo de organização burocrática e ineficiente por meio da qual a escola vem sendo administrada, para substituí-la por uma concepção de gestão mais flexível, capaz de, entre outros fatores, tornar a escola um espaço que eduque para o desenvolvimento das habilidades que seriam requeridas pela sociedade no estágio atual do modo de produção capitalista. Nesse sentido, a reforma da educação deveria desenvolver nos estudantes a capacidade de resolver problemas, de produzir um espírito criativo e flexível para sobreviver aos desafios postos pela modernização da sociedade. Os documentos da reforma expressam concepções de educação e de conhecimento que os apontam como responsáveis pelo aumento da produtividade, pela redução da pobreza, pelo exercício da cidadania e pela inserção do País na nova ordem econômica mundial.

Para construir o consenso em torno das reformas e das políticas públicas pretendidas e, desse modo, efetivar seu papel ideológico, as novas apostas no campo educacional são justificadas pela idéia de que investir na educação é fundamental para a dinamização do crescimento econômico e para a redução da pobreza. A partir disso, as reformas empreendidas são justificadas, portanto, pela idéia de que, na sociedade do conhecimento, segundo Shiroma,

[...] não basta apenas educar, é preciso aprender a empregar convenientemente os conhecimentos adquiridos. A reestruturação produtiva, afirma o discurso, exige que se desenvolvam capacidades de comunicação, de raciocínio lógico formal, de criatividade, de articulação de conhecimentos múltiplos e diferenciados de modo a capacitar o educando a enfrentar sempre novos e desafiantes problemas. Mais ainda, diante da velocidade das mudanças, as requalificações tornam-se imperativas. (SHIROMA et al., 2002, p. 12).

Duarte (2003) denuncia o caráter ideológico dessa perspectiva, denominada sociedade do conhecimento, na qual o que importa é o como se aprende ou o "aprender a aprender", interpretando-a como uma ideologia produzida pelo capitalismo, "A assim chamada sociedade do conhecimento é uma ideologia produzida pelo capitalismo, é um fenômeno no campo da reprodução ideológica do capitalismo. [. . . é uma ilusão que cumpre determinada função ideológica na sociedade capitalista contemporânea." (DUARTE, 2003, p. 14).

$\mathrm{Na}$ medida em que a sociedade do conhecimento se articula aos fins do capital, fica clara a concepção de criatividade e de conhecimento por ela requerida. Duarte (2003, p. 12) afirma:

Quando educadores e psicólogos apresentam o 'aprender a aprender' como síntese de uma educação destinada a formar indivíduos criativos é importante atentar para um detalhe fundamental: essa criatividade não deve ser confundida com busca de transformações radicais na realidade social, busca de superação radical da sociedade capitalista, mas sim criatividade em termos de capacidade de encontrar novas formas de ação que permitam melhor adaptação aos ditames da sociedade capitalista.

Mantidos os pressupostos do neoliberalismo na escola por meio da pedagogia do "aprender a

Dialogia, São Paulo, v. 7, n. 1, p. 113-120, 2008. 
aprender", ter-se-á a completa destruição da concepção de ser humano como um ser que se constrói no interior das relações sociais, em um espaço definido de conflitos e de contradições. O ser humano, entendido como ser social ou produto das relações sociais, sucumbe na definição implícita dessa concepção pedagógica de autocriação do homem compreendido como produto de si mesmo. Nessa concepção ideológica de auto-criação, na circunscrição do conhecimento ao eu de cada um, elimina-se o outro como interlocutor. Caberia aqui afirmar que, a partir da reforma do pensamento efetuado com a reforma da educação básica, sugere-se o desapego teórico, pois, pela valorização da forma como se aprende, tem-se em vista a formação de um sujeito aberto a mudanças, flexível.

Buscando a inserção do país na nova ordem econômica internacional, pela educação propõe-se que, além da transmissão dos conteúdos elementares, a escola forme o cidadão para o pluralismo, para o senso de tolerância, de solidariedade, de solução pacífica dos conflitos. Note-se, que, nessa nova ordem, as condições necessárias para a incorporação do Brasil nessa realidade são as seguintes: conhecimentos elementares e princípios que aceitem e, mais do que isso, em nome da chamada eqüidade, pactuem com a racionalidade do capital, cujo componente intrínseco é a desigualdade social entre pessoas ou países.

\section{Considerações finais}

A articulação existente entre as reformas do Estado e da educação, com a implantação da eficiência mercadológica e a introdução de mecanismos que têm como objetivo atingir essa eficiência e, portanto, a incorporação dos pressupostos de flexibilização das formas de gestão e controle do trabalho, é explicada pela necessidade, posta pelo modo de produção capitalista, de preservar a interação entre as diferentes organizações sociais para que reproduzam uma dada lógica de comportamento, de disciplina.

Portanto, com as reformas do Estado e da educação, ocorridas no Brasil, na década de 1990, a ênfase na educação passou a ser a eficiência do funcionamento das instituições escolares e a qualidade de seus resultados. Procurou-se ressaltar a influência de organismos internacionais na proposição e no estabelecimento das diretrizes das reformas estabelecidas para o aparelho de Estado como um todo, em seu processo de reforma. Mediante esse quadro, a educação assume papel de relevância na formação dos cidadãos nesta sociedade marcada pelo consumo e pela flexibilização das relações sociais e de trabalho.

A partir da análise dos documentos que propõem as reformas da gestão e da educação básica, pode-se afirmar que se utilizam mecanismos que visam impor a eficiência mercadológica acompanhada de uma nova racionalidade. Essa eficiência e essa racionalidade partem de enfoques ditos inovadores e flexíveis no campo da gestão, do controle e da organização do trabalho. Esse controle é efetivado por meio da descentralização, autonomia, participação e avaliação de resultados.

\section{The reform of the State} and the Education in the decade of 1990: the re-function of the school by implementation
of the marketing efficiency This article intends to analyze some possible impacts about the pedagogical work in school institu- 
tions of the Brazilian public educational net passed by the State and the education reforms implemented in Brazil at the decade of 1990, structuralized by means of the principles of the theory of the socialliberalism, that makes a critical one to the State of the social welfare, making it responsible for the crisis. Acting as a lawyer the necessity of remodelling the State and its institutions for correcting the distortions and increasing its efficiency, pointing to be this the possible way with respect to Brazil to insert if in the new organization in the production way capitalist. Considering the educational field as constituent part of the capitalist State, also it will be object of the proposals of reform of the State, in the measure where the speech of the reformists affirms to be its inefficiency the responsible one for the failure pertaining to school.

Key words: Educational policy. Marketing efficiency. Schools management pertaining. The reforms of the State and the Education.

\section{Nota}

1 Artigo escrito como conclusão da disciplina Práticas Escolares e Profissão Docente, do PPGE-Uninove, $1^{\circ}$ semestre 2007, sob a coordenação da Profa. Dra. Ivanise Monfredini

\section{Referências:}

BANCO MUNDIAL. Prioridades e estratégias para a educação. Estudo setorial do Banco Mundial. Versão preliminar. Maio de 1995.

BRASIL. Ministério da Administração Federal e Reforma do Estado - MARE. Plano Diretor da Reforma do Aparelho do Estado. Brasília, DF, nov. 1995 . Ministério da Educação e Cultura. Lei de Diretrizes e Bases da Educação Nacional $\mathrm{n}^{\circ} 9.394$, de 20 de dezembro de 1996.
CEPAL, UNESCO. Educação e conhecimento: eixo de transformação produtiva com eqüidade. Brasília, DF: IPEA/CEPAL/INEP, 1992

DELORS, Jacques (Org.). Educação: um tesouro a descobrir. Relatório para a Unesco da Comissão Internacional sobre Educação para o século XXI. Brasília, DF: MEC, 1999.

DUARTE, N. As pedagogias do "aprender a aprender" e algumas ilusões da assim chamada sociedade do conhecimento. Revista Brasileira de Educação, n. 18, set./out./nov./dez. 2003

MELLO, G. N. Social democracia e educação: teses para discussão. São Paulo: Cortez; Autores Associados, 1990. (Polêmicas do Nosso Tempo, n. 35).

NEVES, L. M. W. Educação e política no Brasil de hoje. 2. ed. São Paulo: Cortez, 1999.

MÉSZÁROS, I. Para além do capital: rumo a uma teoria da transição. Campinas: Editora da UNICAMP/ São Paulo: Boitempo, 2002.

OLIVEIRA, D. A. Mudanças na organização e na gestão do trabalho na escola. Idéias - Revista do Instituto de Filosofia e Ciências Humanas da Unicamp, Campinas, 1998/1999.

SHIROMA, E; MORAES, M. C. M; EVANGELISTA, O. Política educacional, Rio de Janeiro: DP\&A, 2002

TORRES, R. M. Melhorar a qualidade da educação básica? As estratégias do Banco Mundial. Tradução Mônica Corrulón. In: TOMMASI, Lívia de; WARDE, Mirian Jorge; HADAD, Sérgio (Org.). O Banco Mundial e as políticas educacionais. 3. ed. São Paulo: Cortez, 2000.

recebido em 14 ago. 2007 / aprovado em 13 mar. 2008

Para referenciar este texto:

NAIDER FILHO, E. A reforma do Estado e da educação na década de 1990: a refuncionalização da escola via implementação da eficiência mercadológica.

Dialogia, São Paulo, v. 7, n. 1, p. 113-120, 2008. 